\title{
PENGARUH MOTIVASI DAN PELATIHAN TERHADAP KINERJA KARYAWAN PD. HARUM JAYA
}

\author{
Elga Nolisa dan Edalmen \\ Program Studi S1 Fakultas Ekonomi Universitas Tarumanagara, Jakarta \\ elga.115160490@stu.untar.ac.id
}

\begin{abstract}
The purpose of this study is to determine the effect of motivation and training on. The population taken from this study were all employees of PD. Harum Jaya, amounting to 65 people. The sample selected using total sampling, namely the entire population. The data processing technique uses structural equation modeling which is assisted by the SmartPLS version 3 program. The results of this study are that motivation has a positive and insignificant effect on performance while training has a positive and significant effect on the performance of PD employees. Harum Jaya.
\end{abstract}

Keywords: Motivation, Training, Perfomance.

Abstrak: Tujuan dari penelitian ini adalah untuk mengetahui pengaruh motivasi dan pelatihan terhadap kinerja. Populasi yang diambil dari penelitian ini adalah seluruh karyawan PD. Harum Jaya yang berjumlah 65 orang. Sampel dipilih dengan menggunakan total sampling yaitu seluruh populasi. Teknik pengolahan data menggunakan pemodelan persamaan struktural yang dibantu dengan program SmartPLS versi 3. Hasil dari penelitian ini adalah motivasi berpengaruh positif dan tidak signifikan terhadap kinerja sedangkan pelatihan berpengaruh positif dan signifikan terhadap kinerja pegawai PD. Harum Jaya.

Kata Kunci: Motivasi, Pelatihan, Kinerja.

\section{LATAR BELAKANG}

Pada masa pandemi covid 19 saat ini, setiap perusahaan diharuskan memiliki keunggulan yang lebih dari perusahaan kompetitor yang lain. Karyawan harus memiliki motivasi kerja yang tinggi dan produktif. Perusahaan juga harus mampu meningkatkan kemampuan kerja para karyawannya agar kinerja perusahaan dapat meningkat. Karyawan yang mempunyai motivasi kerja yang tinggi akan dapat diperoleh dengan penerapan konsep dan teknik manajemen sumber daya manusia yang tepat untuk mencapai tujuan, baik secara individu maupun organisasi. Selain motivasi faktor lain yang mempengaruhi kinerja karyawan yaitu pelatihan kerja. Pelatihan kinerja sangat dibutuhkan dalam mengembangkan keterampilan dari karyawan, terutama agar supaya kinerja karyawan lebih meningkat dari standar yang sudah ditetapkan oleh perusahaan, Kemunduran suatu perusahaan salah satu penyebabnya adalah ketidakmampuan menghadapi pesaing yang berkecimpung di bidang sejenisnya. Dalam kondisi seperti ini perusahaan manapun harus melakukan pelatihan kerja yang efektif dan efisien agar kinerja perusahaan dapat mengalami peningkatan.

PD. Harum Jaya adalah sebuah perusahaan dagang yang memproduksi berbagai jenis produk makanan yang dalam operasional produksinya pada masa pandemi ini menghdapai berbagai permasalahan. Motivasi kerja karyawan menurun seiring dengan berkurangnya permintaan dari kosumen akibat pandemi, Kinerja perusahaan juga menurun yang ditandai oleh penurunan produksi dan omzet penjualan. Oleh karena itu maka penulis melakukan penelitian pada PD Harum Jaya ini untuk melihat pengaruh motivasi dan pelatihan terhadap kinerja perusahaan. 


\section{KAJIAN TEORI}

Mangkunegara (2010: 67) mendefinisikan kinerja karyawan adalah hasil kerja secara kualitas dan kuantitas yang dicapai oleh seseorang karyawan dalam melaksanakan tugasnya sesuai dengan tanggung jawab yang di berikan kepadanya. Sedangkan Simanjuntak, (2011: 11) menyatakan bahwa kinerja seseorang di pengaruhi oleh berbagai faktor tang dikelompokkan atas tiga golongan yaitu, kompensasi, faktor dukungan organisasi, dan faktor psikologis. Hersey and Blanchard (1993) mengartikan kinerja sebagai fungsi dari motivasi dan kemampuan. Sehingga agar dapat menyelesaikan suatu tugas atau pekerjaan, seseorang harus memiliki tingkat kemampuan tertentu serta derajat kesediaan. Menurut Wibowo (2011:48) kinerja merupakan tanggung jawab setiap individu terhadap pekerjaan, membantu mendefinisikan harapan kinerja, mengusahakan kerangka kerja bagi supervisor dan pekerja saling berkomunikasi. Dari beberapa definisi tersebut dapat disimpulkan bahwa kinerja karyawan adalah hasil kerja yang dicapai seseorang dalam melaksanakan tugas-tugasnya tertentu secara berencana pada waktu dan tempat yang bersangkutan.Semua perusahaan mengingikan penacapaian kinerja yang maksimal dari setiap anggota karyawannya. Karena berkaitan dengan pencapaian tujuan perusahaan, maka karyawan dituntut untuk bekerja maksimal. Oleh karna itu, kinerja karyawan sangat perlu diperhatikan dengan jalan melaksanakan kajian terhadap faktor yang mempengaruhi kinerja itu sendiri.

Malayu Hasibuan (2005 : 143) mendefinisikan motivasi adalah dorongan atau pemberian daya penggerak yang menciptakan kegairahan kerja seseorang agar mereka mau bekerja sama, bekerja efektif, dan terintegrasi dengan segala daya upayanya untuk mencapai kepuasan. Sedangkan Slameto (2003:2) mengemukakan bahawa motivasi merupakan suatu proses usaha yang dilakukan oleh individu untuk memperoleh suatu perubahan tingkah laku yang baru secara keseluruhan sebagai hasil pengalaman individu itu sendiri dalam interaksi dengan lingkungannya. Dari definisi tersebut dapatlah disimpulkan bahwa apabila karyawan memiliki motivasi semangat yang tinggi maka akan mempunyai pengagruh terhadap terhadap kinerja karyawan dan sangat membantu tercapainya tujuan perusahaan. Hal ini dapat dilakukan dengan cara memberikan perhatian yang khusus untuk memenuhi kebutuhan karyawan yang sudah mejadi hak mereka. karena dengan dipenuhinya kebutuhan mereka akan dapat memberikan kinerja yang optimal.

Mondy (2008:210) mendefinisikan pelatihan merupakan serangkaian aktivitas yang dirancang guna memberi pengetahuan dan keterampilan yang dibutuhkan para pembelajar untuk dapat melaksanakan pekerjaan mereka pada saat itu. Sedangkan Simamora dan Hendry (2004:274) mengartikan pelatihan merupakan proses yang mencoba untuk menyediakan bagi seorang karyawan informasi, keahlian dan pemahaman atas organisasi dan tujuan dimana pelatihan dirancang untuk meningkatkan keahlian, pengetahuan, pengalaman, atau perubahan sikap seseorang. Menurut Dessler (2008:280) pelatihan dimaksudkan untuk memberikan keterampilan yang dibutuhkan bagi karyawan baru maupun karyawan yang sudah ada dalam melakukan pekerjaannya. Dari beberapa pengertian ini dapat disimpulkan bahwa Pelatihan adalah proses atau serangkaian aktivitas yang dirancang untuk meningkatkan keahlian atau memberikan keterampilan bagi suatu karyawan baru ataupun yang lama. Pelatihan kerja sangat dibutuhkan dalam mengembangkan keterampilan dari karyawan, terutama dari kinerja karyawan agar lebih meningkat dari standar yang sudah ditetapkan oleh perusahaan

Motivasi sangat mempengaruhi kinerja seseorang ketika sedang bekerja. Apabila seseorang bekerja dalam organisasi ataupun perusahaan yang memiliki nilai - nilai yang kuat maka karyawan dapat termotivasi untuk menjadi lebih produktif. Pelatihan yang diberikan dapat 
berbentuk intrinstik maupun ekstrinstik. Jika karyawan termotivasi dan mendapatkan pelatihan dengan baik, maka organisasi dengan langsung akan mencapai tujuannya. Hasil penelitian yang dilakukan oleh Winda Kartika hari Susanta (2020), Abraham Samuel Kaengke Bernhard Tewal, Yantje Uhing (2018) Galih Kusuma (2015), dan Munparidi, (2012) menemukan bahawa terdapat pengaruh positif dan signifikan motivasi dan pelatihan terhadap kinerja karyawan. Artinya kinerja karyawan dapat ditingkatkan dengan pemberian motivasi dan pelatihan

Berdasarkan pemikiran tersebut, penulis mengambil kesimpulan bahwa kinerja sangat dipengaruhi oleh motivasi dan pelatihan. Dalam kerangka pemikiran ini, peneliti akan menggambarkan alur keterkaitan variabel independent yaitu Motivasi dan Pelatihan dengan variabel dependen yaitu kinerja sebagai berikut

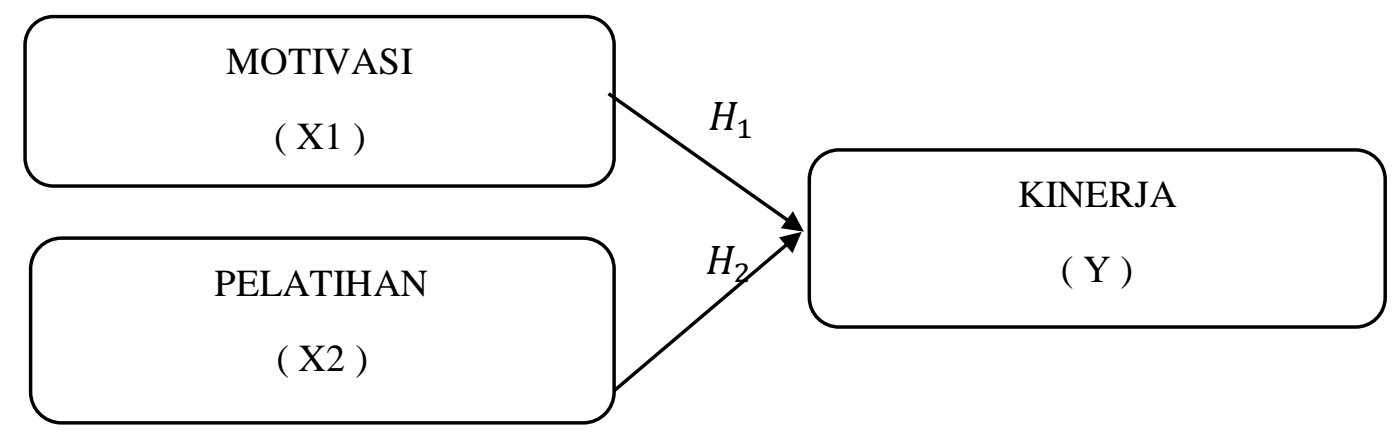

Gambar 1. Model Penelitian

Berdasarkan kajian teori diatas maka hipotesis dalam penelitian ini adalah sebagai berikut :

$H_{1}$ : Terdapat pengaruh positif Motivasi terhadap Kinerja Karyawan PD. Harum Jaya $\mathrm{H}_{2}$ :Terdapat pengaruh positif Pelatihan terhadap Kinerja Karyawan PD. Harum Jaya

\section{METODOLOGI}

Populasi dalam penelitian ini seluruh karyawan PD. Harum Jaya dan Teknik pemilihan sampel yang digunakan dalam penelitian ini adalah Total sampling dimana seluruh sebanyak jumlah yang bekerja di PD. Harum Jaya, di Tangerang. Sebagai pertimbangan pemilihan sampel. Instrumen yang digunakan adalah kuisioner secara online menggunakan google form. Data diolah menggunakan metode Partial Least Square (PLS) dengan aplikasi Smart-PLS versi 3.0. Penelitian ini menggunakan tiga variabel yaitu, motivasi, pelatihan dan kinerja. Variabel motivasi memiliki 5 indikator yang diadaptasi dari Julianto \& Hendriani (2014), Pelatihan memiliki 4 indikator yang diadaptasi dari Siagian (2004). Kinerja memiliki 7 indikator yang diadaptasi dari Anwar Prabu Mangkunegara ( 2014 ). Semua konstuk diukur menggunakan skala Likert 5 poin. Dan menganalisi data dengan cara Uji validitas : loading factors $>0,50$, AVE > 0,50 dan Uji Reliabilitas = composite reliability > 0,70, alpha Cronbach > 0,60, Pengujian koefisien determinasi $\left(\mathrm{R}^{2}\right)$,Pengujian effect size $\left(\mathrm{f}^{2}\right), \mathrm{Uji}$ Goodness of Fit, dan Pengujian hipotesis. 


\section{HASIL ANALISIS DATA}

Analisis data dilakukan melalui uji outer model dan inner model. Berikut gambar hasil pengujian outer model yang menggunakan analisis PLS Algorithm:

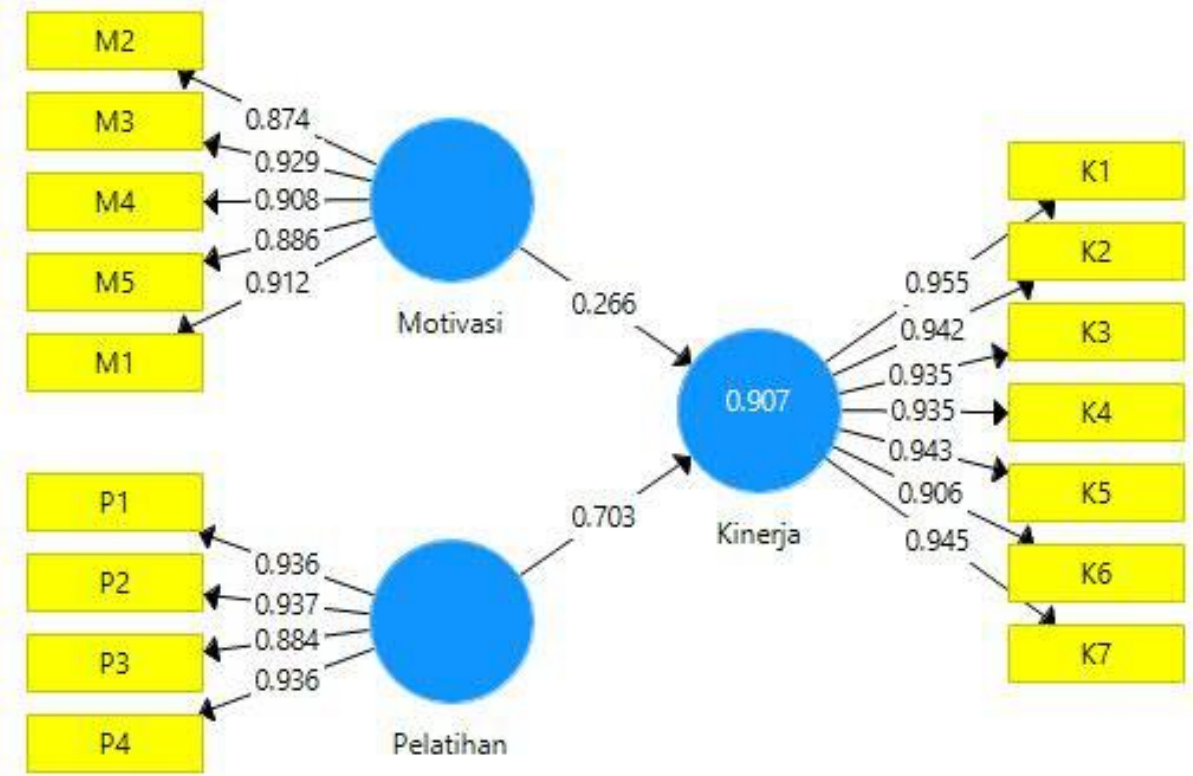

Gambar 2. Hasil Analisis PLS Algorithm

Dari gambar diatas dapat dilihat bahwa semua indikator pada setiap variable mempunyai loading factor yang lebih besar dari 0,5 dan mempunyai nilai AVE seperti yang ditunjukkan oleh table berikut

Tabel 1. Tabel AVE

\begin{tabular}{|c|c|c|}
\hline Variabel & Average Variance Extraced & Keterangan \\
\hline Motivasi & 0,814 & Valid \\
\hline Pelatihan & 0,853 & Valid \\
\hline Kinerja & $\mathbf{0 , 8 7 9}$ & Valid \\
\hline
\end{tabular}

Uji validitas dilakukan dengan melihat nilai AVE. Apabila nilai AVE lebih besar atau sama dengan 0,5 (Hair et al., 2012) maka instrumen penelitian tersebut dapat dikatakan valid. Hasil pengujian menunjukkan bahwa semua item dalam penelitian ini memiliki nilai AVE lebih besar dari 0,5. Dengan demikian, semua item dalam penelitian ini adalah valid. Perhitungan Cronbach' Alpha disajikan di table berikut:

Tabel 2. Tabel Cronbach's Alpha

\begin{tabular}{|l|l|l|}
\hline & Cronbach's Alpha & Keterangan \\
\hline Motivasi & $\mathbf{0 . 9 4 3}$ & Reliebel \\
\hline Pelatihan & $\mathbf{0 . 9 4 2}$ & Reliebel \\
\hline
\end{tabular}




\begin{tabular}{|l|l|l|}
\hline Kinerja & $\mathbf{0 . 9 7 7}$ & Reliebel \\
\hline
\end{tabular}

Uji reliabilitas instrumen dalam PLS menggunakan Cronbach's Alpha dari blok indikator yang mengukur konstruknya. Suatu instrumen dikatakan reliabel jika nilai Cronbach's Alpha berada di atas tingkat ambang 0,7 (Nunnally, 1967). Hasil Pengujian menunjukkan bahwa semua item dalam penelitian ini memiliki nilai Cronbach's Alpha lebih besar dari 0,7.

Uji koefisien determinasi dilakukan dengan melihat nilai R Square. Nilai R square digunakan untuk menilai variasi pengaruh variabel independen terhadap variabel dependen. Hasil pengujian menunjukkan bahwa nilai $\mathrm{R}$ Square untuk variabel kinerja adalah 0,907. Artinya, variabel kinerja dapat dijelaskan oleh variabel motivasi dan pelatihan sebesar 90,7 persen sementara sisanya sebesar 9,3 persen dijelaskan oleh variabel lain yang tidak terdapat dalam penelitian ini.

Uji Hipotesis dilakukan dengan menggunakan metode bootstrapping Pengujian hipotesis dilakukan dengan membandingkan nilai p-value dengan tingkat kepercayaan $(\alpha)$ sebesar 0,05 dengan nilai T statistic > 1,96. Berikut adalah gambar dari hasil bootstrapping

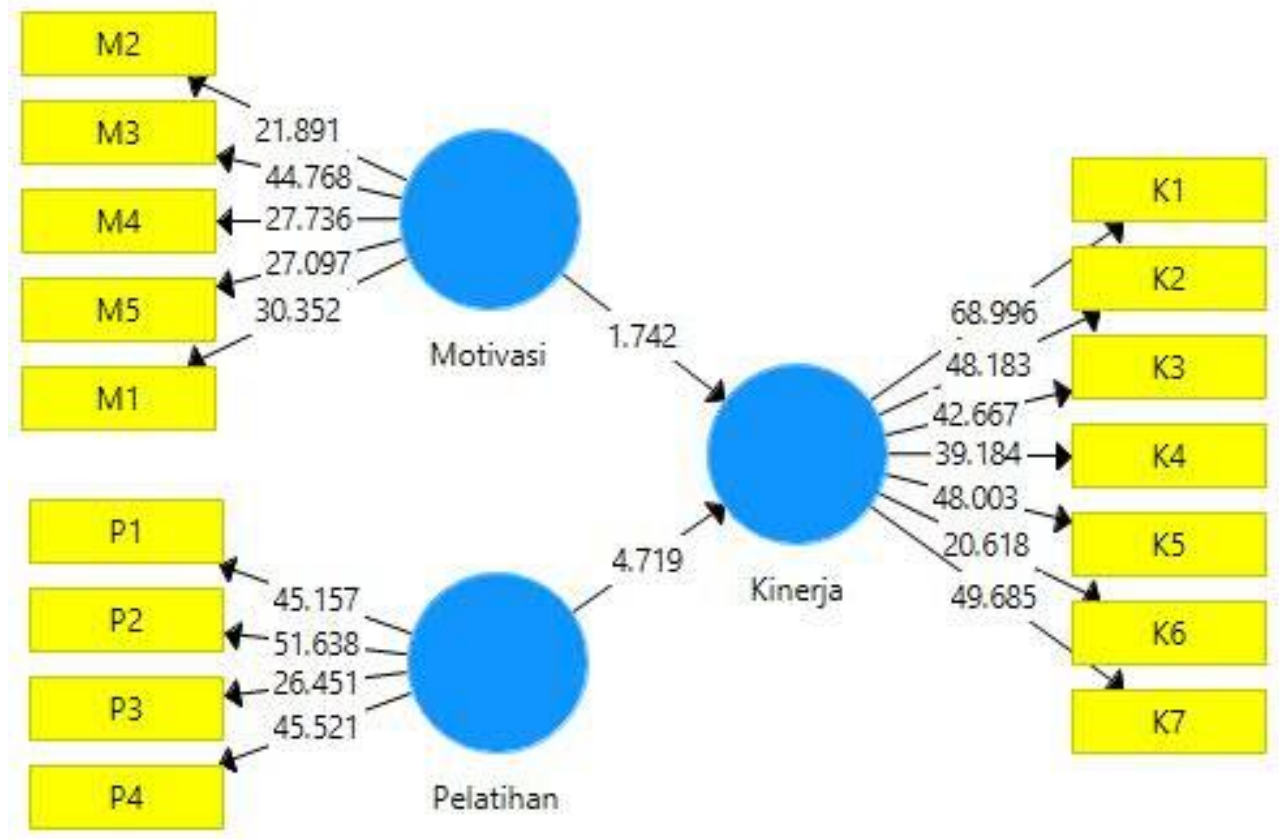

Gambar 3. Hasil Bootstrapping

Tabel berikut menunjukkan hasil dari uji hipotesis yang diperoleh dari bootstrapping

Tabel 3. Pengujian Hipotesis (Path Coefficient)

\begin{tabular}{|l|l|l|l|l|l|}
\hline & $\begin{array}{l}\text { Original } \\
\text { Sample }\end{array}$ & $\begin{array}{l}\text { Sample } \\
\text { Mean }\end{array}$ & $\begin{array}{l}\text { Standard } \\
\text { Deviation }\end{array}$ & T Stastics & P - Values \\
\hline
\end{tabular}




\begin{tabular}{|ll|c|c|c|c|c|}
\hline $\begin{array}{l}\text { Motivasi } \\
\text { Kinerja }\end{array}$ & $\rightarrow$ & 0.266 & 0.313 & 0.160 & 1.711 & 0.097 \\
\hline $\begin{array}{l}\text { Pelatihan } \\
\text { Kinerja }\end{array}$ & $\rightarrow$ & 0.703 & $\mathbf{0 . 6 5 8}$ & $\mathbf{0 . 1 5 4}$ & 4.635 & $\mathbf{0 . 0 0 0}$ \\
\hline
\end{tabular}

Sumber: Olahan data SmartPLS Ver 3 for Windows (2020)

Koefisien jalur (path coefficient) adalah signifikan apabila nilai $\mathrm{p}$-value $<0,05$ dan nilai $\mathrm{t}$ statistic lebih besar dari 1,96.(Haryono, 2017). Hasil pengujian untuk H1 menemukan path coefficient sebesar 0,266 artinya terdapat pengaruh positif variable motivasi terhadap kinerja sebesar 0,266. Artinya jika motivasi semakin meningkat maka kinerja juga akan meningkat demikian sebaliknya jika motivasi menurun maka kinerja juga semakin menurun. Akan tetapi apabila dilihat secara statistik diketahui bahwa t statistik nilainya adalah 1,711 yang < dari 1,96 dan $p$ value sebesar 0,097 yang > 0,05 yang berarti pengaruh motivasi terhadap kinerja adalah tidak signifikan. Dengan demikian dapat disimpulkan bahawa hipotesis 1 tidak diterima. Untuk uji $\mathrm{H} 2$ diperoleh angka path coefficient sebesar 0,703 , yang menunjukkan terdapat pengaruh positif varibel motivasi terhadap kinerja. Jika pelatihan ditingkatkan maka kinerja juga akan meningkat. Apabila dilihat hasil uji statistic diperoleh nilai t statistic sebesar 4,635 yang > dari 1,96 dan pa value sebesar 0,000 yang < dari 0,05 . Hal ini menyimpulkan bahwa $\mathrm{H} 2$ yang menyatakan terdapat pengaruh positif dan sugnifikan pelatihan terhadap kinerja dapat diterima.

\section{DISKUSI}

Penelitian ini menemukan bahwa motivasi berpengaruh positif dan tidak signifikan terhadap kinerja. Dengan demikian, semakin besar motivasi yang dimiliki seorang karyawan berbanding lurus dengan kinerja karyawan. Hasil penelitian ini sesuai dengan penelitian sebelumnya yang dilakukan oleh Indra Marjaya dan Fajar Pasaribu (2019). yang menyatakan bahwa terdapat pengaruh positive dan tidak signifikan motivasi terhadap kinerja. Hasil ini berbeda dengan menelitian yang dilakukan oleh Winda Kartika hari Susanta (2020), Abraham Samuel Kaengke Bernhard Tewal Yantje Uhing (2018) Galih Kusuma dkk (2015), dan Munparidi, (2012) yang menemukan bahwa terdapat pengaruh positif dan signifikan motivasi dan kinerja karyawan. Artinya artinya jika motivasi karyawan meningkat maka kinerja yang diberikan juga semakin efektif dan efisien.

Jika diperhatikan nilai loading factor dari indicator motivasi ini maka nilai tertinggi ada pada indicator M3 yaitu kesempatan yang diberikan perusahaan utnuk mengembangkan karir dan indikator dengan nilai terendah adalah M2 yaitu pemberian bonus dan insentif. Ini dapat dijadikan kebijakan perusahaan untuk peningkatan motivasi karyawan dimasa yang akan datang.

Hasil Penelitian ini juga menemukan bahwa terdapat pengaruh positif dan signifikan pelatihan terhadap kinerja. Artinya peningkatan frekuensi atau jumlah jam pelatihan yang diberikan terhadap karyawan akan dapat meningkatkan kinerja perusahaan. Hasil ini sejalan dengan penelitian yang dilakukan oleh Winda Kartika hari Susanta (2020), Abraham Samuel Kaengke Bernhard Tewal Yantje Uhing (2018) Galih Kusuma dkk (2015) dan Munparidi, (2012) yang menemukan bahwa terdapat pengaruh positif dan signifikan pelatihan dan kinerja karyawan. Dan berbeda dengan penelitian oleh Edwin Amin Budi Susilo (2012) dengan judul "Pengaruh Pelatihan dan Pemberian Insentif terhadap Kinerja Karyawan melalui Komitmen Organisasi " 
Hasil loading factor, menunjukkan bahwa indikator yang mempunyai penagruh terbesar pada variable pelatihan ini adalah P2 yaitu perubahan kemampuan berpikir karyawan dan yang paling terendah adalah P3 perubahan sikap karyawan. Untuk secara keseluruhan penilaian kinerja perusahaan ini indikator yang paling menentukan adalah K1 yaitu, tentang kerapihan kerja karyawan, tentunya ini berkaitan dengan hasil produk yang dihasilkan untuk dijual kepada para pelanggan. Adapun indikator kinerja K6 tentang jalinan kerjasama masih perlu ditingkatkan lagi dimasa yang akan dating akan kinerja karyawan dapat meningkat.

\section{PENUTUP}

Hasil penelitian ini merekomendasikan beberapa hal bagi perusahaan PD Harum Jaya diantaranya adalah bahwa untuk meningkatkan kinerja perusahaan maka motivasi karyawan menjadi salah satu faktor yang harus diperhatikan Meningkatnya motivasi kerja karyawan diharapkan mampu utnuk meningkatkan kinerja. Pengembangan karir karyawan memang sudah cukup baik akan tetapi pemberian bonus dan insentif adalah salah satu kunci untuk peningkatan kinerja karyawan. Selain itu pemberian pelatihan yang semakin meningkat baik secara frekuensi maupun lamanya jam pelatihan adalah faktor lain yang juga harus diperhatikan oleh perusahaan untuk meningkatkan kinerjanya. Pelatihan yang berorientasi untuk perubahan cara berpikir karyawan memang sudah cukup baik, tetapi pelatihan yang berorientasi kepada sikap mental karyawan haruslah lebih ditingkatkan lagi. Jalinan Kerjasama antar sesama karyawan dan antar karyawan dengan atasan juga perlu ditingkatkan lagi untuk peningkatan kinerja dimasa mendatang.

Untuk penelitian lanjutan disarankan untuk menambahkan variable lainnya yang belum terdapat dalam penelitian ini misalnya kompensasi, kepuasan kerja, lingkungan kerja dan variable variable lainnya. Penambahan jumlah sampel juga sangat dianjurkan dan juga dengan menggunakan sampel perusahaan yang berbeda mungki akan menemukan hasil yang berbeda pula.

\section{DAFTAR PUSTAKA}

Agusta, L., \& Sutanto, E. (2013). PENGARUH PELATIHAN DAN MOTIVASI KERJA TERHADAP KINERJAKARYAWAN CV HARAGON SURABAYA. Jurnal Ekonomi Vol. 1, , No.3.

Blanchard, \& Hersey. (1993). Management For Organizational Behaviour. Singapore.

Dessler, G. (2008). Human Resource Management. New Jersey: Pearson.

Hair, J. F., Black, W. C., Babin, B. J., \& Anderson, R. E. (2014). Multivariate Data Analysis. Seventh Edition: Pearsons.

Hasibuan, M. (2005). Manajemen Sumber Daya Manusia, Edisi Revisi. Jakarta: PT. Bumi Aksara.

Julianto, \& Hendriani. (2014). Pengaruh Budaya Organisasi dan Motivasi Kerja Terhadap Kepuasan Kerja dan Kinerja Pegawai pada Kantor Wilayah Direktorat Jenderal Bea dan Cukai (DJBC) Riau dan Sumatera Barat. Jurnal Ekonomi Volume 22.

Kaengke, A. S., Tewal, B., \& Uhing, Y. (2020). Pengaruh Pengembangan Karir, Pelatihan Dan Motivasi Terhadap KinerjaKaryawan Pada PT Air Manado. Jurnal Riset, Vol 6 No.1.

Kartika, W., \& Sutanta, H. (2020). PENGARUH MOTIVASI DAN PELATIHAN TERHADAP KINERJA PERAWAT. Jurnal Administrasi Bisnis, Vo. 9 No.2.

Kusuma, G. (2015). PENGARUH MOTIVASI DAN PELATIHAN TERHADAP KINERJA (STUDI PADA KARYAWAN PT.PLN (PERSERO) DISTRIBUSI JAWA TIMUR AREA MALANG). Jurnal Administrasi Bisnis, Vol.22 No.1. 
Mangkunegara. (2010). Manajemen Sumber Daya Manusia Perusahaan. Bandung: PT. Remaja Rosdakarya.

Mondy, W. (2008). Manajemen Sumber Daya Manusia. Jakarta: Erlangga.

Munparidi. (2012). Pengaruh Kepemimpinan, Motivasi, Pelatihan, dan Lingkungan Kerja Terhadap Kinerja Karyawan pada Perusahaan Daerah Air Minum Tirta Musi Kota Palembang. Jurnal Orasi Bisnis, Edisi ke-VII, 47-54.

Nunally. (1967). Psychometric Theory. New York: Mc Graw Hill.

Prayitno, E. (1989). motivasi dalam belajar. Jakarta: Departemen Pendidikan dan Kebudayaan. Siagian, S. (2004). Manajemen Sumber Daya Manusia. Jakarta: Bumi Aksara.

Simamora, \& Hendry. (2004). Manajemen Sumber Daya Manusia. Yogyakarta: STIE YKPN. Simanjuntak, P. (2011). Manajemen Evaluasi Kinerja ed 3. Jakarta: Fakultas UI.

Slameto. (2003). Belajar dan Faktor-Faktor Yang Mempengaruhinya. Jakarta: PT. Rineka Cipta.

Wibowo. (2011). Manajemen Perubahan Edisi Ke 3. Jakarta: Rajawali. 